\title{
Effects of Silicone Nasal Septal Splints and a Polyvinyl Alcohol Sponge After Septoplasty on Postoperative Pain and Pain During Pack Removal
}

Tolga ERSÖZLÜ1 iD, Adem ÇAKMAK² iD

${ }^{1}$ Department of Otorhinolaryngology, Namık Kemal University School of Medicine, Tekirdağ, Turkey

${ }^{2}$ Clinic of of Otorhinolaryngology, Sarkkamış State Hospital, Kars, Turkey

\section{ABSTRACT}

Objective: To compare silicone nasal septal splints with integral airway and a polyvinyl alcohol (PVA) sponge after septoplasty in terms of patient comfort (both with the pack in place and during removal) and postoperative complications.

Methods: This study involved 169 patients who underwent septoplasty without additional nasal procedures due to nasal septal deviation. They were allocated into two groups. Group A comprised 90 patients who underwent septoplasty and who were packed with silicone nasal septal splints. Group B comprised 76 patients who underwent septoplasty and who were packed with a PVA sponge. They were removed on the second postoperative day. Patients were asked to record pain levels using a visual analog scale (VAS).

Results: The patients in the groups had similar mean ages: 29.77 years (range, 19-74 years) and 23.77 years (range, 21-37 years) in Group A and Group B, respectively ( $>0.05)$. VAS scores were significantly lower in Group A than in Group B at the $1^{\text {st }}, 2^{\text {nd }}, 4^{\text {th }}, 8^{\text {th }}$, $12^{\text {th }}, 24^{\text {th }}, 48^{\text {th }}$, and $72^{\text {nd }}$ postoperative hours $(\mathrm{p}<0.0001)$. There were significantly higher pain levels associated with PVA sponge pack removal than with silicone nasal septum splint removal (average pain scores: 3.57 vs. 1.99 , respectively; $\mathrm{p}<0.05$ ).

Conclusion: Intranasal septal splints with integral airway result in less postoperative pain during removal without increasing postoperative complications; thus, they can be used as an effective alternative to PVA sponge packing after septoplasty.

Keywords: Septal surgery, nasal pack, nasal pack removal, silicone nasal splint, polyvinyl alcohol sponge, pain

\section{Introduction}

Nasal septal surgery is one of the most frequently performed operations in otorhinolaryngology clinics $(1,2)$. Nasal packing is one of the effective tools for septal support and avoiding adhesion after septal surgery. In recent years in particular, silicone nasal septal splints with integral airway have been used to reduce pain and increase patient comfort postoperatively (3-5). The usage of nasal packing after septoplasty may rarely cause life-threatening complications (6-8), but nasal packing also prevents some complication such as adhesion formation, bleeding, hematoma, and septal perforation $(3,9,10)$. These complications may be minimized by using nasal packing after surgery and during postoperative care and choosing the best nasal packing option $(6,7)$. During or after septal operations, effective postoperative pain control is essential because pain may decrease the quality of life. The most common morbidity associated with packing is postoperative pain and pain during its removal (2-5, 9-11). Patients usually feel anxious about pain before surgery.

Postoperatively nasal packing materials, such as vaseline gauze, glove fingers, Oxycel (Woundcare Ltd., Manchester, UK), Gelfoam (Pharmacia \& Upjohn, Michigan, USA), Merocel (Medtronic, Connecticut, USA), silastic sheets, fibrin glue, synthetic polyurethane foam, Rapid Rhino (Smith \& Nephew Inc., Austin, USA), and silicone intranasal splints, are used (2-7, 10-12).

Suture techniques are applied without using nasal packing $(2,9,10,13,14)$. Worldwide, the type of nasal packing material to be used after septoplasty is unclear. Though the use of nasal splints in recent years has increased, comparative studies on them are not sufficient.

Cite this article as: Ersözlü T, Çakmak A. Effects of Silicone Nasal Septal Splints and a Polyvinyl Alcohol Sponge After Septoplasty on Postoperative Pain and Pain During Pack Removal. Bezmialem Science 2018; 6: 43-7.

Address for Correspondence: Tolga ERSÖZLÜ, Namık Kemal Üniversitesi Tıp Fakültesi, KBB Kliniği, Tekirdağ, Türkiye 
We aimed to evaluate silicone nasal septal splints with integral airway and the polyvinyl alcohol (PVA) sponge Merocel (Medtronic, Connecticut, USA) after septoplasty with regard to patient's pain both with the pack in place and during removal as well as postoperative complications.

\section{Methods}

This study involved 169 patients who underwent only septoplasty due to nasal septal deviation between July 2011 and March 2013. The study protocol was approved by Gülhane Military Medical Academy, Medical Faculty and Hospital Ethics Committee (05/07/2011-176). All patients were informed on surgical risks, possible complications related to the operation, and the research protocol before they signed the informed consent form. All patients were older than 18 years. Exclusion criteria were as follows: immunodeficiency or any sign of infection at the time of operation previous history of any type of nasal surgery, and presence of nasal polyps or chronic sinusitis. Patient selection for surgery was based on the clinical history, rhinology examination results, and nasal endoscopy findings. Preoperative laboratory evaluations included complete blood count, thrombin time, prothrombin time, and thromboplastin time.

\section{Subjects}

The patients were divided into two groups:

Group A comprised 90 patients who underwent septoplasty and who were packed with mupirocin cream (Bactroban 2\% cream, Glaxo Smith Kline, Istanbul, Turkey)-soaked silicone nasal septal splints with integral airway (DOYLE splint; Boston Medical Products, MA, USA) in both nasal cavities. It was removed on the second postoperative day.

Group B comprised 76 patients who underwent septoplasty and who were packed with mupirocin cream (Bactroban 2\% cream; GlaxoSmithKline, Istanbul, Turkey)-soaked PVA sponge Merocel (Medtronic, Connecticut, USA) with integral airway in both nasal cavities. It was removed on the second postoperative day.

\section{Surgical procedure}

All septoplasty procedures were performed under general anesthesia. They were conducted using a headlight. At the beginning of anesthesia, $20 \mathrm{mg} / \mathrm{mL}$ of lidocaine hydrochloride and $0.0125 \mathrm{mg} / \mathrm{mL}$ of epinephrine hydrochloride (JETOKAİNE 2 ML; Adeka, Istanbul, Turkey) were administered to all patients to aid homeostasis. A local anesthetic agent was infiltrated into the nasal septum bilaterally in the submucoperichondrial-subperiosteal plane. A hemitransfixion incision was made in all patients. Deviated osteochondral parts were removed, reshaped, and placed back again. All incisions were sutured using 3/0 polyglytone (Capros$\mathrm{yn}^{\mathrm{TM}}$; Medtronic, Connecticut, USA) Both materials were packed in both nasal cavities. The patients were blinded to the type of packs used; however, the surgeons were not blinded.
All patients were given $1 \mathrm{~g}$ of intravenous cefazolin. Postoperatively, patients were given $500 \mathrm{mg}$ of paracetamol three times a day orally.

\section{Pain measurement}

No other perioperative analgesic medication was used. To determine the level of postoperative pain, a continuous $10-\mathrm{cm}$ visual analog scale (VAS) was used, with " 0 " indicating no pain and " 10 " indicating the most severe pain. Patients were asked to mark the severity of their pain on the scale at predefined time points (at the $1^{\text {st }}, 2^{\text {nd }}, 4^{\text {th }}, 8^{\text {th }}, 12^{\text {th }}, 24^{\text {th }}, 48^{\text {th }}$, and $72^{\text {nd }}$ postoperative hours and at the removal time ( $48^{\text {th }}$ hour $)$ ), and scores were measured and recorded in millimeters.

Patients were given $500 \mathrm{mg}$ of paracetamol three times a day. The prescriber was blinded to the type of nasal packs used. Postoperative complications were recorded in both groups. All patients were followed up until the $20^{\text {th }}$ postoperative day.

\section{Statistical analysis}

Raw data obtained from the questionnaire with application data were used to be converted and analyzed with the statistical software program IBM Statistical Package for Social Sciences (IBM Corp.; Armonk, NY, USA) for Windows 20.0. Descriptive statistical analysis was performing using the mean $\left(\mathrm{X}^{-}\right)$, standard deviation, minimum, frequency, and percentage. Research data were examined with the Kolmogorov-Smirnov test and graphical representation. Quantitative data were analyzed used Mann-Whitney U Test and independent sample $t$ test. The paired sample $t$ test and Wilcoxon test were used to analyze repeated measures. Results were evaluated in terms of $95 \%$ confidence interval and significance of $\mathrm{p}<0.05$.

\section{Results}

The silicone nasal splint group (Group A) included 90 patients and the sponge pack group (Group B) included 79 patients. Data of all patients were included in the statistical analysis. The patients in the groups had similar mean ages: 29.77 years (range, 19-74 years) and 23.77 years (range, 2137 years) in Group A and Group B, respectively ( $>0.05$ ). All patients were symptom-free at the follow-up visit on the $20^{\text {th }}$ postoperative day.

VAS scores were significantly lower in Group A than in Group $\mathrm{B}$ at the $1^{\text {st }}, 2^{\text {nd }}, 4^{\text {th }}, 8^{\text {th }}, 12^{\text {th }}, 24^{\text {th }}, 48^{\text {th }}$, and $72^{\text {nd }}$ postoperative hours $(\mathrm{p}<0.0001)$ (Figure 1). There were significantly higher pain levels associated with Merocel (Medtronic, Connecticut, USA) pack removal than with silicone nasal splint removal (average pain scores: 3.57 vs. 1.99, respectively; $\mathrm{p}<0.05$ ) (Figure 2).

Hematoma was observed in three patients in Group A and two patients in Group B. Further, in Group B, purulent discharge was observed in two patients. Hematoma was drained, and nasal packing was done for two additional days. Patients were treated with $1000 \mathrm{mg}$ of amoxicillin two times a day orally for seven more days. 
All patients recovered by the $14^{\text {th }}$ day. There was no nausea and vomiting-related difference between the groups. None of the patients presented any complaints related to pain, nausea, or vomiting in the follow-up visit on the $14^{\text {th }}$ day postoperatively. There was no fever in any of the patients. There was no statistically significant difference between the groups due to postoperative complications ( $p>0.05$ ). No cardiovascular or neurological complications were observed in both groups.

\section{Discussion}

Nasal obstruction is a common problem and is usually treated with septoplasty (15). Septoplasty is one of the most common operation in the field of otolaryngology $(1,2)$. Pain persists after all surgeries, and it may lead to difficulties for patients trying to return to their routine lives. Many patients' concerns about nasal packs used after septoplasty and pain during the removal of nasal packs $(2,9,14)$. However, in recent years, new surgical procedures and materials render the postoperative process more painless $(9,11,13)$.

Nasal packing is used after septoplasty to control postoperative bleeding, fixate septal cartilage, and reduce adherent mucosa and septal hematoma (3-6). However, nasal packing leads to problems such as pain, mucosal damage, blockage of the Eustachian tube, infection, and dry mouth $(2,3,9,10$, 14). Serious problems such as toxic shock syndrome, cardiac

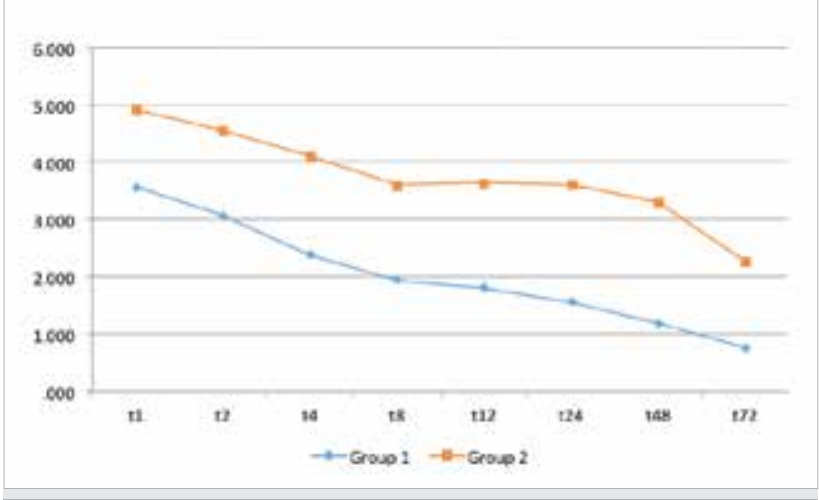

Figure 1. Postoperative pain VAS scores in both groups

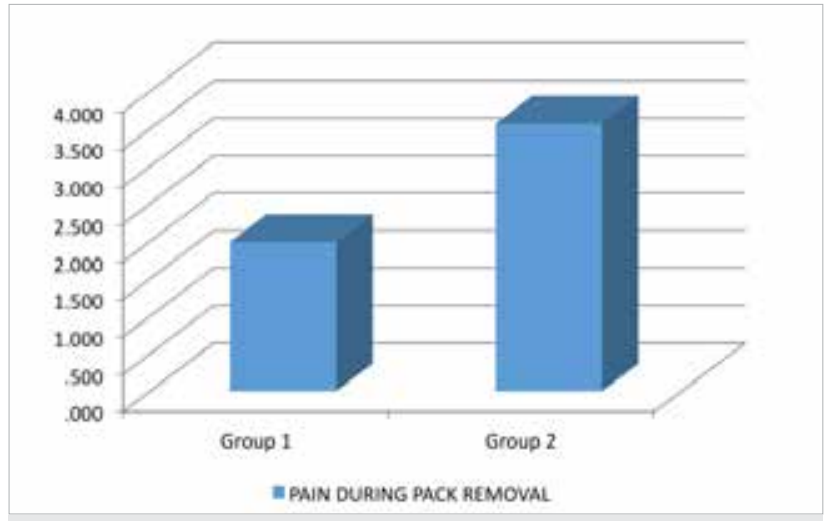

Figure 2. Pain VAS scores during pack removal arrhythmia, and even death have become very rare with the use of antibiotics and comfortable packs and with close monitoring (9).

Worldwide, many types of nasal packs have been used, but a group of physicians used septal suture techniques in their studies instead of packing after septoplasty (2-15). Therefore, there is no consensus on what type of nasal packs need to be used after septoplasty. In our clinic, we used both silicone nasal septal splints with integral airway and a PVA sponge with integral airway after septal surgery; in this study, we aimed to compare the pain levels $72 \mathrm{~h}$ after the operation and at the time of removing the nasal packs. The most disturbing complaints have been reported to be at the time of removing of the pack and the postoperative period. Unlike other studies, we also evaluated pain at the $72^{\text {nd }}$ hour. The VAS scoring system was used for evaluating pain scores. This method has high sensitivity and is easy to use (11). Further, we evaluated both groups in terms of postoperative complications. We determined no significant difference in complications between the two groups.

Merocel is one of the most commonly used and cost-effective nasal packs $(3,5,9)$. However, because nasal packs adhere to the mucosa, bleeding and pain during the time of removal create difficulties $(9,13)$. Other materials have been used to minimize these disadvantages. Hesham et al. (12) conducted a study with Rapid Rhino and Merocel; they made comparisons in terms of pain and complications and found that Rapid Rhino is better in terms of relieving pain during removal and bleeding. Similarly, Series 500 nasal packs, synthetic polyurethane foam, gauze in glove finger, and FloSeal were found to be less painful than Merocel during the removal of nasal packs $(5,11,16-18)$. Acioglu et al. (11) evaluated pain, nasal fullness, and bleeding potential associated with using four nasal packing materials (Merocel, Doyle Combo splint, Merocel clothed with glove finger, and vaseline gauze) and determined that Merocel had the highest pain potential during removal and the highest rate of bleeding following removal. In our study, we compared postoperative discomfort and pain scores between two nasal packing groups. Postoperative pain scores increased in group B (Merocel group), which was in agreement with findings in the literature $(11,12)$. Similar to the above studies, in our study, we observed that group A (nasal splint group) was better than Merocel in terms of reducing postoperative pain scores and pain during removal.

Asaka et al. (3) compared silicone plates with sponge-like packing and found less postoperative pain scores in the silicone plate group. Jung et al. (6) showed that silastic septal splints prevent postoperative adhesion and mucosal erosion and cause less discomfort in the early postoperative period; they also recommended the use of proper septal positioning. Aksoy et al. (7) used internal nasal splints in their study; they compared postoperative early and late bleeding, septal hematoma, and adherent mucosa formation and found that complication rates do not significantly differ according to the 
splint removal time. The patients whose splints were removed at the first and fifth postoperative days had similar complication rates in the study of Aksoy et al. (7). Lubianca-Neto et al. (19) evaluated the rates of hemorrhagic complications after nasal pack removal when left for 24 and $48 \mathrm{~h}$. In their studies, the rate of postoperative complications did not differ according to the time of nasal packing. As emphasized in the literature above, we removed both the PVA sponge Merocel with integral airway and silicone nasal septal splints with integral airway on the second postoperative day.

Yilmaz et al. (8) determined that silicone nasal splints cause less Eustachian tube dysfunction. Septal suture is recommended as an alternative to packing. There are literatures reports that septal sutures is better in terms of postoperative pain and complications and that there is no need to use splints $(2,9,10,13,14,20-23)$. Some of these studies have been conducted before the 2000s; today, thin, flexible, integral airway, and comfortable silicone splints are used. In addition, Kula et al. (24) found that that nasal packs did not affect mucociliary clearance. Özkırış et al. (14) compared trans-septal suturing, nasal splints, and Merocel (Medtronic, Connecticut, USA) and found lesser postoperative pain in the trans-septal suturing group than in the other groups; however, the surgery time was found to be longer in the trans-septal suturing group than in the other groups. There is a lack of consensus regarding the timing of nasal pack removal after septoplasty. Another group that had nasal packing removed the fifth day after the operation may be created to determine the effect of the duration of using the nasal packing on pain. Our study shows that nasal splints was better than the PVA sponge in terms of patient comfort. Therefore, silicone nasal splints can be selected for routine use for patient comfort in septal surgery.

\section{Conclusion}

Nasal packing is used for the reduction of postoperative complications and septal stabilization. After septal surgery, there is no consensus on the methods or the ideal pack to be used. We conclude that intranasal septal splints with integral airway result in less postoperative pain during removal without increasing postoperative complications; thus, they can be used as an effective alternative to the PVA sponge (Merocel) packing after septoplasty.

Ethics Committee Approval: Ethics committee approval was received for this study from the ethics committee of Gülhane Military Medical Academy, Medical Faculty, and Hospital (05/07/2011-176).

Peer-review: Externally peer-reviewed.

Author Contributions: Concept - A.Ç.; Design - A.Ç.; Supervision - A.Ç.; Resource - A.Ç.; Materials - A.Ç.; Data Collection and/ or Processing - T.E.; Analysis and/or Interpretation - T.E.; Literature Search - T.E.; Writing - T.E.; Critical Reviews - T.E.

Conflict of Interest: No conflict of interest was declared by the authors.
Financial Disclosure: The authors declared that this study has received no financial support.

\section{References}

1. Karaman E, Alimoglu Y, Aygun G, Kilic E, Yagiz C. Effect of septoplasty and per-operative antibiotic prophylaxis on nasal flora. B-ENT 2012; 8: 13-9.

2. Ardehali M, Bastaninejad S. Use of nasal packs and intranasal septal splints following septoplasty. Int J Oral Maxillofac Surg 2009; 38: 1022-4. [CrossRef]

3. Asaka D, Yoshikawa M, Okushi T, Nakayama T, Matsuwaki Y, Otori N, et al. Nasal splinting using silicone plates without gauze packing following septoplasty combined with inferior turbinate surgery. Auris Nasus Larynx 2012; 39: 53-8. [CrossRef]

4. Deniz M, Ciftçi Z, Işık A, Demirel OB, Gültekin E. The impact of different nasal packings on postoperative complications. Am J Otolaryngol 2014; 35: 554-7. [CrossRef]

5. Kim YS, Kim YH, Kim NH, Kim SH, Kim KR, Kim KS. A prospective, randomized, single-blinded controlled trial on biodegradable synthetic polyurethane foam as a packing material after septoplasty. Am J Rhinol Allergy 2011; 25: e77-9.

6. Jung Y, Hong JW, Eun YG, Kim MG. Objective usefulness of thin silastic septal splints after septal surgery. Am J Rhinol Allergy 2011; 25: 182-5. [CrossRef]

7. Aksoy E, Serin GM, Polat Ş, Kaytaz A. Removing intranasal splints after septal surgery. J Craniofac Surg 2011; 22: 1008-9. [CrossRef]

8. Yilmaz MS, Guven M, Buyukarslan D, Kaymaz R, Erkorkmaz U. Do Silicone Nasal Septal Splints with Integral Airway Reduce Postoperative Eustachian Tube Dysfunction? Otolaryngol Head Neck Surg 2012; 146: 141-5.

9. Dubin MR, Pletcher SD. Postoperative packing after septoplasty: Is it necessary? Otolaryngol Clin North Am 2009; 42: 279-85.

10. Cukurova I, Cetinkaya EA, Mercan GC, Demirhan E, Gumussoy M. Retrospective analysis of 697 septoplasty surgery cases: packing versus trans-septal suturing method ACTA Otorhinolaryngol Ital 2012; 32: 111-4.

11. Acıoğlu E, Edizer DT, Yiğit Ö, Onur F, Alkan Z. Nasal septal packing: which one? Eur Arch Otorhinolaryngol 2012; 269: 1777-81.

12. Hesham A, Ghali A. Rapid Rhino versus Merocel nasal packs in septal surgery. J Laryngol Otol 2011; 125: 1244-6. [CrossRef]

13. Banglawala SM, Gill M, Sommer DD, Psaltis A, Schlosser R, Gupta M. Is nasal packing necessary after septoplasty? A metaanalysis. Int Forum Allergy Rhinol 2013; 3: 418-24. [CrossRef]

14. Ozkırış M, Kapusuz Z, Saydam L. Comparison of nasal packs with transseptal suturing after nasal septal surgery. Am J Otolaryngol 2013; 34: 308-11. [CrossRef]

15. Sykes JM, Kim JE, Shaye D, Boccieri A. The importance of the nasal septum in the deviated nose. Facial Plast Surg 2011; 27: 413-21. [CrossRef]

16. Bresnihan M, Mehigan B, Curran A. An evaluation of Merocel and Series 5000 nasal packs in patients following nasal surgery: A prospective randomised trial. Clin Otolaryngol 2007; 32: 352-5. [CrossRef]

17. Prabhu V, Kaushik V, Rhodes S, Tay H. Foam nasal packs: A prospective, randomised, patient-controlled study. Rhinology 2007; 45: 242-7.

18. Jameson M, Gross CW, Kountakis SE. FloSeal use in endoscopic sinus surgery: Effect on postoperative bleeding and 
synechiae formation. Am J Otolaryngol 2006; 27: 86-90. [CrossRef]

19. Lubianca-Neto JF, Sant'anna GD, Mauri M, Arrarte JL, Brinckmann CA.. Evaluation of time of nasal packing after nasal surgery: A randomized trial. Otolaryngol Head Neck Surg 2000; 122: 899-901. [CrossRef]

20. Campbell JB, Watson MG, Shenoi PM. The role of intranasal splints in the prevention of post-operative nasal adhesions. J Laryngol Otol 1987; 101: 1140-3. [CrossRef]

21. Von Schoenberg M, Robinson P, Ryan R. The morbidity from nasal splints in 105 patients. Clin Otolaryngol Allied Sci 1992; 17: 528-30. [CrossRef]
22. Malki D, Quine SM, Pfleiderer AG. Nasal splints, revisited. J Laryngol Otol 1999; 113: 725-7. [CrossRef]

23. Lemmens W, Lemkens P. Septal suturing following nasal septoplasty, a valid alternative for nasal packing? Acta Otorhinolaryngol Belg 2001; 55: 215-21.

24. Kula M, Yuce I, Unlu Y, Tutus A, Cagli S, Ketenci I. Effect of nasal packing and haemostatic septal suture on mucociliary activity after septoplasty: An assessment by rhinoscintigraphy. Eur Arch Otorhinolaryngol 2010; 267: 541-6. [CrossRef] 